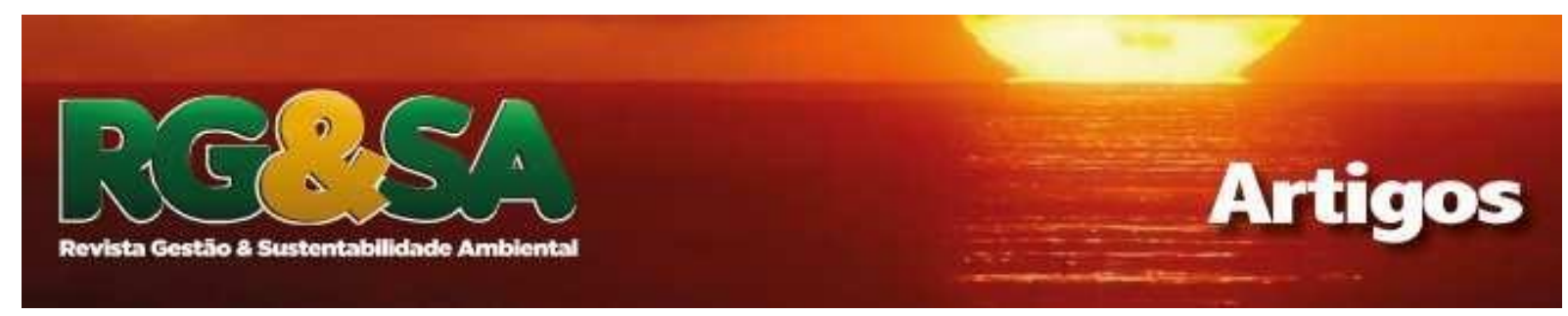

\title{
EXTRAFISCALIDADE E ENERGIA SOLAR FOTOVOLTAICA: O USO DA TRIBUTAÇÃO AMBIENTAL NA PROMOÇÃO DA SUSTENTABILIDADE
}

DOI: 10.19177/rgsa.v9e0I2020677-691

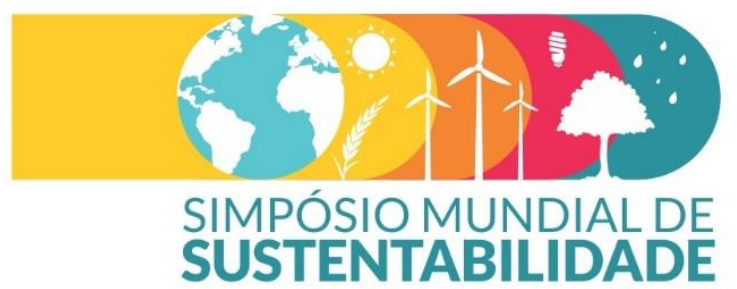

\author{
Igor Talarico da Silva Micheletti ${ }^{1}$ \\ Danilo Hungaro Micheletti ${ }^{2}$ \\ Natiele Cristina Friedrich ${ }^{3}$ \\ Débora Hungaro Micheletti ${ }^{4}$ \\ Sônia Maria Talarico de Souza ${ }^{5}$ \\ Flavia Piccinin Paz Gubert ${ }^{6}$ \\ Marcelo Wordell Gubert ${ }^{7}$ \\ Glauci Aline Hoffmann ${ }^{8}$
}

\section{RESUMO}

\footnotetext{
${ }^{1}$ Graduando em Direito. Faculdade de Ensino Superior de Marechal Cândido Rondon - PR. igor_talarico@hotmail.com

${ }^{2}$ Mestrando no Programa de Pós-graduação em Bioenergia. Universidade Federal do Paraná. danilohmicheletti@hotmail.com

${ }^{3}$ Graduanda em Direito. Faculdade de Ensino Superior de Marechal Cândido Rondon - PR. natielefriedrich@hotmail.com

${ }^{4}$ Graduanda em Engenharia de Energias Renováveis. Universidade Federal do Paraná. deborahungaromicheletti@gmail.com

${ }^{5}$ Graduada em Pedagogia. Universidade Estadual de Maringá - PR. talaricomar@yahoo.com.br

${ }^{6}$ Doutoranda no Programa de Pós-Graduação em Desenvolvimento Rural Sustentável. Universidade Estadual do Oeste do Paraná.flavia@gubertepaz.com

${ }^{7}$ Doutorando no Programa de Pós-Graduação em Direito. Universidade de Marília - SP.

marcelo@gubertepaz.com

${ }^{8}$ Doutoranda no Programa de Pós-Graduação em Desenvolvimento Rural Sustentável. Universidade Estadual do Oeste do Paraná. glauhoffmann@gmail.com
} 
A extrafiscalidade aplicada ao setor de energia solar fotovoltaica tem o intuito de fomentar a produção energética sustentável no país. O Estado tem o dever de estimular o mercado interno sempre aliado ao desenvolvimento sustentável, estimulando a criação e o fortalecimento de empresas inovadoras, seja para fins de extensão da qualidade de vida da humanidade ou para finalidades comerciais e industriais. Assim, buscou-se analisar se a tributação ambiental é um aliado do direito na busca por sustentabilidade e, portanto, se os tributos ambientais aplicados à energia solar fotovoltaica podem auxiliar a encontrar o equilíbrio entre a proteção e a preservação ambiental. $O$ presente trabalho utilizou-se do método de pesquisas bibliográficas, consultando a doutrina especializada, a legislação vigente e as normativas técnicas da área, caracterizando uma pesquisa qualitativa e descritiva. Deste modo, considera-se que o caminho a percorrer ainda é longo no que tange a concessão de extrafiscalidade que possa estimular políticas públicas efetivas com intuito de incentivar a produção de energia limpa e renovável no país.

Palavras-chave: Energia Fotovoltaica. Desenvolvimento Sustentável. Políticas Públicas.

\section{EXTRAFISCALITY AND PHOTOVOLTAIC SOLAR ENERGY: THE USE OF ENVIRONMENTAL TAXATION IN PROMOTING SUSTAINABILITY}

\section{ABSTRACT}

The extrafiscality applied to the photovoltaic solar energy sector is intended to foment sustainable energy production in the country. The State has a duty to stimulate the internal market always together with sustainable development, stimulating the creation and strengthening of innovative companies, either for the purpose of extending the quality of life of humanity or for commercial and industrial purposes. Thus, it was sought to analyze whether environmental taxation is an ally of law in the pursuit of sustainability and, therefore, whether environmental taxes applied to photovoltaic solar energy can help to find the balance between protection and environmental preservation. The present work used the method of bibliographical research, consulting the specialized doctrine, the current legislation and the technical norms of the area, characterizing in a qualitative and descriptive research. Thus, it is considered that the way to go is still long with regard to granting extrafiscality that can stimulate effective public policies in order to encourage the production of clean and renewable energy in the country.

Key words: Photovoltaic Energy. Sustainable Development. Public Policies.

\section{INTRODUÇÃO}


A energia é um dos pilares essenciais da sociedade atual, sendo necessária no desenvolvimento das atividades humanas em seus mais diversos setores, envolvendo uma grande utilização de recursos naturais.

Os impactos ambientais e seus efeitos na sociedade através do uso da energia e das mudanças climáticas são observados em todo o planeta, tendo adquirido força na última década no que se refere à discussão acerca da utilização de fontes energéticas ambientalmente conscientes.

A princípio, os ideais para o desenvolvimento baseavam-se na ideia de que estes recursos seriam inesgotáveis e, portanto, este processo teve como consequência uma grande deterioração das condições ambientais do planeta.

O desenvolvimento econômico brasileiro não foi diferente, sendo historicamente marcado pela degradação e poluição dos recursos naturais, só havendo preocupação com a sustentabilidade e com a preservação do ambiente nos últimos anos.

A energia solar fotovoltaica foi sendo inserida no mercado energético brasileiro de forma gradual, até o ano de 2012, ela era empregada principalmente em pequenos sistemas isolados ou autônomos, instalados principalmente em locais de difícil acesso não atendidos pela rede elétrica ou em locais onde a instalação de linhas de distribuição se tornava inviáveis.

Um importante passo dado para inserção da energia fotovoltaica no País foi o projeto estratégico Arranjos Técnicos e Comerciais para a Inserção de Geração Solar Fotovoltaica na Matriz Energética Brasileira, lançado pela ANEEL em conjunto com concessionárias de energia elétrica de todo o país com objetivo de promover a criação de usinas experimentais de energia fotovoltaica interligadas ao sistema elétrico nacional.

Busca-se deste modo, identificar, se a extrafiscalidade aplicada por meio de leis e projetos políticos de tributação ambiental à energia solar fotovoltaica, pode auxiliar a encontrar o equilíbrio entre a proteção e a preservação ambiental, buscado assim incentivo a mudança cultural de utilização dos recursos naturais e na gestão do bem comum, possibilitando a inserção da energia solar fotovoltaica como uma fonte mais efetiva de energia elétrica na matriz nacional.

Sendo assim, tem-se que é possível melhorar a qualidade de vida da população mundial aliada ao crescimento econômico sustentável, propondo-se um uso planejado 
e eficiente dos recursos energéticos disponíveis, além do incentivo tributário para o desenvolvimento de novas tecnologias de geração de energia.

\section{METODOLOGIA}

Para o desenvolvimento do presente estudo foi utilizado a pesquisa bibliográfica, exploratória descritiva, onde serão analisados artigos, doutrinas, com viés descritivo e análise documental.

Foi utilizado o método qualitativo. A pesquisa é do tipo exploratória, com a finalidade de explorar todos os campos com possibilidade de retirar informações necessárias para obtenção de resultados satisfatórios.

\section{DESENVOLVIMENTO SUSTENTÁVEL E DIREITO À INOVAÇÃO}

Neste contexto globalizado do mundo, é essencial que os recursos ambientais devam ser corretamente geridos, levando-se em consideração que os padrões de costumes de mercado tendem a mudar, podendo afetar a produção e o consumo.

Assim, qualquer política que venha atuar em prol da sustentabilidade deve sempre equilibrar entre os pilares que a constituem: o ambiental, o social e o econômico. Essa harmonização dos objetivos visa trazer o bem-estar no presente e no futuro, tratando-se de um princípio constitucional que, independente de regulação legal, possui eficácia direta e imediata (ALMEIDA, 2017).

Após a Conferência de Estocolmo, a preocupação mundial com a proteção ao meio ambiente e com novas formas de desenvolvimento sustentável aumentaram significativamente.

Até a década de 1970, ainda se tinha a ideia de que recursos naturais eram infinitos ou facilmente renováveis, mas que caiu por terra durante a conferência e trouxe profundas mudanças na nova política preservacionista do meio ambiente (BETTES et al., 2017).

Neste novo cenário, observa-se que o desenvolvimento econômico dos países está necessariamente associado à preservação e à sustentabilidade da utilização dos recursos naturais, tendendo a buscar o equilíbrio e a elevação na qualidade de vida dos seres humanos, os quais dependem da disponibilidade dos recursos ambientais para garantir a conservação de sua própria vida no planeta. 
Sendo assim, é necessário resguardar as orientações defendidas pela Comissão Mundial sobre Meio Ambiente e Desenvolvimento das Nações Unidas, conferindo efetividade aos princípios e valores básicos tutelados em nossa ordem internacional (ALMEIDA, 2017).

No Brasil tivemos grandes avanços como nossa Carta Magna de 1988, pioneira na questão da proteção dos recursos naturais no país, o direito a um meio ambiente ecologicamente equilibrado foi elevado à categoria de direito fundamental do ser humano. O caput do art. 225 da nossa Carta Magna determina o direito ao meio ambiente ecologicamente equilibrado como um direito humano fundamental, que consiste em bem de uso comum do povo e essencial para garantir a sadia qualidade de vida da população (AZEVEDO e BRAGA JUNIOR, 2013, p. 79).

A tarefa de equilibrar meio ambiente e economia nem sempre é fácil, até porque o homem sempre buscou o lucro, tendo na história e nos reflexos atuais a comprovação de tal conduta, sendo que, após anos de exploração e industrialização é recente a discussão da sociedade acera dos efeitos do "desenvolvimento" em busca de equilíbrio econômico.

Entretanto, o Direito à inovação é inato ao ser humano, que busca desenvolver seus potenciais e é considerado hoje um alicerce essencial para o desenvolvimento socioeconômico de um Estado (ALMEIDA, 2017).

São três os agentes considerados indispensáveis para o sistema de inovação: o Estado, as instituições de ensino e pesquisa e as instituições privadas. A soma de forças desses agentes possibilita a produção de inovação e de transformá-la em desenvolvimento, resguardando sempre a preocupação com as consequências oriundas desse processo para que o desenvolvimento da inovação seja aliado ao desenvolvimento sustentável (ALMEIDA, 2017).

No Brasil a preocupação com a inovação tecnológica vem sendo debatido há décadas, mas o direito vigente muitas vezes é rotulado como inibidor da inovação.

Entretanto, essas discussões levaram ao Projeto de Lei 2.177/2011, que deu origem em 2016 o projeto de criação do Código Nacional de Ciência, Tecnologia e Inovação, um marco legal que regula os estímulos destinados ao desenvolvimento científico, à capacitação cientifica e tecnológica, à pesquisa e à inovação.

Assim surgiu a proposta de Emenda Constitucional no 85, que alterou e adicionou dispositivos na Constituição Federal para atualizar o tratamento de ciência, tecnologia e inovação (MENDES et al., 2016). 
A EC-85 é responsável por incluir expressamente a inovação entre as atividades a serem incentivadas pelo Estado. O Artigo 23 da Constituição Federal diz que "é competência comum da União, dos Estados, do Distrito Federal e dos Municípios: [...] V - proporcionar os meios de acesso à cultura, à educação, à ciência, à tecnologia, à pesquisa e à inovação" (BRASIL, 1988).

Alguns outros artigos da Constituição Federal foram alterados e outros incluídos para abranger textos relativos ao desenvolvimento de inovação, valendo destacar o parágrafo único do artigo 219:

\begin{abstract}
Art. 219. O mercado interno integra o patrimônio nacional e será incentivado de modo a viabilizar o desenvolvimento cultural e socioeconômico, o bemestar da população e a autonomia tecnológica do País, nos termos de lei federal.

Parágrafo único. O Estado estimulará a formação e o fortalecimento da inovação nas empresas, bem como nos demais entes, públicos ou privados, a constituição e a manutenção de parques e polos tecnológicos e de demais ambientes promotores da inovação, a atuação dos inventores independentes e a criação, absorção, difusão e transferência de tecnologia (BRASIL, 1988).
\end{abstract}

Em outras palavras, o Estado tem o dever de estimular o mercado interno, sempre aliado ao desenvolvimento sustentável, estimulando a criação e o fortalecimento de empresas inovadoras, seja para fins de extensão da qualidade de vida da humanidade ou para finalidades comerciais e industriais.

\title{
4 TRIBUTAÇÃO AMBIENTAL E ENERGIA SOLAR FOTOVOLTAICA
}

Uma questão de grande relevância na geração distribuída no Brasil consiste na relação com o direito tributário nacional e com a cobrança de tributos no setor. Tem sido amplamente discutido sobre como o direito tributário tem influenciado o desenvolvimento do setor no país.

A tributação possui duas principais funções, no qual a primeira e mais comum consiste na chamada função fiscal dos tributos com objetivo de abastecer os cofres públicos com o necessário para que o Estado venha custear as despesas e desenvolver seus objetivos, já a segunda função é conhecida como extrafiscal, que ocorre quando a tributação busca outros fins além da arrecadação de recursos para os cofres públicos, mas visa intervir em assuntos específicos que o Estado acredita merecer tal intervenção (CAVALCANTI, 2017). 
A extrafiscalidade é o emprego de instrumentos tributários que visam a finalidade não arrecadatória, mas de cunho incentivador ou inibidor de comportamentos, para que se cumpra outros preceitos constitucionais consagrados, como a proteção ao meio ambiente (CORBETTA, 2017).

Tendo em vista que o meio ambiente é um direito fundamental, o Estado tem responsabilidade por tutelar este direito, devendo criar políticas públicas ambientais, aplicar sansões e criar mecanismos que incentivem o desenvolvimento sustentável (ALMEIDA, 2017).

Sendo assim, visar um futuro sustentável baseado na preservação do meio ambiente e na manutenção do desenvolvimento sustentável são metas incontestáveis. Portanto, o Estado tem um papel crucial para o desenvolvimento de ações que possam combater os retrocessos e ao mesmo tempo programar novas políticas públicas que ajudem nesse desenvolvimento.

Dentre os papéis do Direito está o de implementar políticas públicas, com a intenção ordenada e coordenada do Estado na atividade econômica, sendo o direito tributário um importante instrumento para tal fim, motivo pelo qual vem se consolidando o tributo ambiental (CORBETTA, 2017, p. 46).

$\mathrm{Na}$ busca pela consolidação do direito fundamental com o desenvolvimento sustentável, há um papel de extrema importância na mão do Estado, pois o Estado é financiado por tributos de cunho arrecadatório mas também tem como função implementar a tributação com finalidade extrafiscal, os quais devem respeitar os princípios constitucionais, com objetivo de que os tributos ambientais possam cumprir o papel de proteção e conservação ambiental (WEDY, 2017).

Nesse sentido, os tributos ambientais pretendem encontrar o equilíbrio entre a proteção e a preservação ambiental. $O$ tributo ambiental continua tendo objetivo arrecadador de recursos, os quais deverão ser utilizados na consecução de tal fim. Assim, este tributo visa coibir, desanimar as pessoas de cometer danos que possam a prejudicar o meio ambiente, podendo tratar os tributos ambientais como aqueles imbuídos de motivação ambiental (CORBETTA, 2017).

Existem dois grandes grupos quando se fala sobre tributação ambiental visando um meio ambiente equilibrado: a imposição de tributos ambientais e a criação de incentivos à produção sustentável.

A primeira tem enfoque no controle da conduta dos agentes, sendo que a tributação incidente sobre atividades nocivas ao meio ambiente possui funções 
nitidamente extrafiscal porque visa proteger o meio ambiente e toda a biodiversidade, tutelando o meio ambiente como um direito fundamental de terceira dimensão devido sua grande importância.

No segundo grupo, o Estado desenvolve seus deveres com a sociedade, pois a sustentabilidade ambiental deve estar baseada não somente em tributar atividades nocivas e poluidoras, mas pautada em políticas públicas que visem a solidariedade sincrônica com a geração atual e a solidariedade diacrônica com as gerações futuras (WEDY, 2017).

O Estado moderno acaba assumindo papel regulador da atividade econômica, mesmo havendo a liberdade de iniciativa, pois esbarram nos limites constitucionais que norteiam a vida em sociedade.

Essas atividades econômicas que podem ser nocivas ao desenvolvimento social, humano e ambiental acabam por serem tuteladas pelo Estado que, através de instrumentos normativos, regulam as atividades (MONTERO, 2014).

Ao mesmo tempo em que todos possuem o direito de usufruir de um meio ambiente equilibrado, todos têm o dever de contribuir com a sua preservação e, através do Estado, a tributação ambiental faz com que cada particular seja chamado a seu dever público de preservar e proteger o meio ambiente, com políticas públicas de incentivo a comportamentos ecologicamente corretos, mas com pagamentos de receitas que visem o cumprimento da finalidade ambiental (WEDY, 2017).

Igualmente, a tributação pode ser utilizada para reduzir as nocividades e prejuízos ao meio ambiente de acordo com a Política Nacional de Mudanças do Clima - PNMC (Lei 12.187/2009):

\footnotetext{
Art. 6 São instrumentos da Política Nacional sobre Mudança do Clima: [...] $\mathrm{VI}$ - as medidas fiscais e tributárias destinadas a estimular a redução das emissões e remoção de gases de efeito estufa, incluindo alíquotas diferenciadas, isenções, compensações e incentivos, a serem estabelecidos em lei específica. (BRASIL, 2009).
}

Isenções fiscais podem ser utilizadas para o desenvolvimento sustentável, incluindo as desonerações na produção de energia e no desenvolvimento de inovações e tecnologias que visam o aprimoramento da matriz energética brasileira.

A utilização dos tributos como forma de reparar ou evitar danos ambientais oriundos da atividade econômica encontra fundamentação na Constituição Federal de 1988 em dois principais momentos, no art. 225, caput, onde impõe ao Poder Público 
e à coletividade o dever de defender e preservar o meio ambiente, e no art. 170, que dispõe acerca da ordem econômica, que tem por fim assegurar a todos existência digna observando entre outros princípios o da defesa do meio ambiente (BRASIL, 1988).

Assim, pode-se estabelecer como princípio da atividade econômica a defesa do meio ambiente, inclusive mediante tratamento diferenciado conforme o impacto ambiental dos produtos e serviços, e de seus processos de elaboração e prestação (SEBASTIÃO, 2006).

\section{EXTRAFISCALIDADE E POLÍTICAS PÚLICAS NO BRASIL}

Dentro do Direito Tributário existem várias espécies de tributos, como impostos, taxas, contribuições de melhoria, empréstimos compulsórios e contribuições especiais. Tratando de energia elétrica, há o PIS/PASEP e o imposto de Contribuição para o Financiamento da Seguridade Social (COFINS) ambos de cunho federal incidindo sobre a tarifa.

Já no âmbito estadual, há o Imposto sobre a Circulação de Mercadorias e Serviços (ICMS). Estes impostos são considerados grandes barreiras no desenvolvimento do setor fotovoltaico, visto que eles não são totalmente isentos na maioria dos casos e incidem sobre a energia elétrica que é injetada na rede pública que, posteriormente, retorna para a unidade consumidora (CAVALCANTI, 2017).

A tributação ambiental buscou desenvolver políticas públicas de proteção ambiental, as quais foram pautadas em diversos setores como no de energia solar fotovoltaica, onde inúmeros benefícios tentam auxiliar no desenvolvimento deste setor no país.

Dentre estas políticas públicas nacionais, podem ser citados os descontos na Tarifa de Uso dos Sistemas de Transmissão (TUST) e na Tarifa de Uso dos Sistemas de Distribuição (TUSD), o Convênio no 101, de 1997, do Conselho Nacional de Política Fazendária (CONFAZ), o Regime Especial de Incentivos para o Desenvolvimento da Infraestrutura (REIDI) e o Programa de Apoio ao Desenvolvimento Tecnológico da Indústria de Semicondutores (PADIS), que incentivam o setor de energias renováveis no Brasil (SILVA, 2013). 
Outro importante aliado do setor de energia solar fotovoltaico é a extrafiscalidade sobre o Imposto sobre Produtos Industrializados (IPI), que incide sobre produtos industrializados nacionais e importados.

Regulamentado pelo Decreto $\mathrm{n}^{0}$ 7.212, de 15 de junho de 2010, que legislou os aspectos da incidência desse imposto. Ele também tem respaldo constitucional no art. 153, IV da CF/88: "Compete a União instituir impostos sobre: [...] IV - produtos industrializados" (BRASIL, 1988).

\begin{abstract}
É bem conhecido o fato de que o Imposto sobre Produtos Industrializados (IPI) é um tributo de competência da União, muito utilizado na implementação de objetivos que não meramente arrecadatórios. A incidência do IPI pode estimular ou desestimular comportamentos e, por causa disso, pode - se afirmar que esse imposto possui um caráter fortemente extrafiscal. No noticiário e em nosso dia a dia de consumidores observamos com frequência a utilização do IPI como instrumento de Política Econômica. (LO VISCO, 2017, p. 479).
\end{abstract}

Com enfoque nessa característica extrafiscal, observa-se que o imposto é seletivo em função da essencialidade dos produtos e não cumulativo, de forma a não sobrecarregar a cadeia produtiva. Em relevante perspectiva, o princípio da seletividade pela essencialidade do produto está previsto no art. $153, \S 3^{\circ}$ da Constituição Federal, ao qual concede benefícios ou não, baseado na necessidade ou essencialidade dos produtos (OLIVEIRA, 2017).

A industrialização ou montagem de painéis solares se encaixa perfeitamente ao inciso III do Art. 4ํㅡㄹ do Decreto 7.212/2010, pois os benefícios se estendem aos insumos dos painéis fotovoltaicos que, juntos, resultam em um novo produto.

Neste sentido o IPI beneficia os módulos solares fotovoltaicos, entretanto deixa de fora os inversores e estruturas metálicas que compões os chamados kits fotovoltaicos (OLIVEIRA, 2017).

A isenção do IPI tem sido um grande aliado no desenvolvimento do setor, além deste há o ICMS que tem trazido maior viabilidade ao consumidor que optar por gerar sua própria energia. O ICMS como tributo está genericamente previsto no artigo 155, inciso II da Constituição Federal, a qual outorga a competência de instituir esse imposto aos Estados e Distrito Federal.

Já no $§ 3^{\circ}$ do mesmo artigo, fica definido que somente incidirá sobre a energia elétrica o ICMS, o imposto de importação e o imposto de exportação, equiparando a energia elétrica às mercadorias. Assim, o ICMS incide sobre a compra de energia pelo consumidor final, titular das unidades consumidoras (BRASIL, 1988). 
Alguns dos principais obstáculos da microgeração e minigeração distribuída estão intrinsicamente ligados a incidência de ICMS na energia injetada na rede e que é usada como forma de compensação pela energia consumida posteriormente, como também a cobrança de Contribuição para Custeio do Serviço de Iluminação Pública (COSIP).

Para viabilizar a utilização de energia solar fotovoltaica no país, após a revisão da $\mathrm{RN}$ no 687/2015, o Estado efetivou um convênio através do CONFAZ, o convênio ICMS 16, de 22 de abril de 2015, no qual dava competência a cada uma das Unidades Federadas a conceder isenção nas operações internas relativas à circulação de energia elétrica, as quais possuíssem geração distribuída no sistema de compensação de energia.

Com isso os Estados que aderiram ao convênio, o ICMS incide somente sobre a diferença entre a energia consumida e a energia injetada na rede, sendo normalmente computado mês a mês. Todos os estados já aderiram o convênio do Confaz (MONZONI, 2018).

Os Estados do Paraná, Amazonas e Santa Catarina, foram os últimos Estados a integrarem o convênio, o qual foi firmado na $302^{a}$ Reunião Extraordinária do CONFAZ e celebraram o Convênio ICMS no 42/2018, cuja finalidade foi a adesão dos referidos Estados ao Convênio ICMS no 16/2015, que tem como objetivo a isenção do ICMS sobre a micro e mini geração de energia elétrica geradas por fontes renováveis e que forem enviadas a rede de distribuição.

Os Estados ficam livres para legislarem internamente a regulamentação deste benefício. No caso do Paraná, a Assembleia Legislativa havia aprovado um projeto que regulamentava esse benefício, a PL 378/2015, entretanto a governadora em exercício Cida Borghetti vetou o projeto de Lei, alegando em seu veto a inconstitucionalidade da Lei, pois a iniciativa gera despesa ou renúncia fiscal, não apontando as devidas compensações.

Desta feita, a governadora efetuou a regulação via decreto, estipulando que a isenção tenha validade de 48 meses, como uma medida provisória, e será encaminhado um novo texto legislativo à Assembleia para ser votado, para garantir a isenção por força de Lei (BREMBATTI, 2018).

Um aliado extrafiscal do setor solar fotovoltaico se deu com a Lei 11.484/2007, na qual se pode destacar a reduções a $0 \%$ nas alíquotas do Imposto de Importação (II), Imposto sobre Produtos Industrializados (IPI), Contribuições do Programa de 
Integração Social (PIS) e de Financiamento da Seguridade Social (COFINS) na aquisição local ou importada de máquinas, equipamentos, aparelhos, instrumentos utilizados na implantação dos investimentos industriais.

Podendo se aplicar essa isenção tributária aos insumos e bem como ferramentas de software. Dentro do setor de solar fotovoltaico existem os incentivos de IPI e PIS/COFINS, os quais impactam diretamente na indústria brasileira.

Após esses incentivos, houve a publicação da Lei 13.169/2015 que, com objetivo tributário ambiental, concedeu isenção de PIS/COFINS sobre a energia produzida em geração distribuída e injetada na rede, cujo crescimento é preponderantemente da energia solar fotovoltaica (VALADÃO e CARNAÚBA, 2017).

$\mathrm{Na}$ esfera dos tributos federais que alcançar o setor de energia elétrica, temos a Contribuição para o PIS/Pasep e a Contribuição para Financiamento da Seguridade Social (COFINS).

Antes do advento da Lei 13.169/2015 os tributos de PIS/Pasep e COFINS eram cobrados com base no consumo bruto da unidade consumidora, sem levar em consideração a energia que fosse injetada na rede da concessionaria. Contudo, após a referida lei, se passou a cobrar PIS e COFINS apenas do consumo líquido da unidade consumidora.

Entretanto, com a edição da Lei no 13.169, de 6 de outubro de 2015, passouse a isentar a parcela da energia fornecida pela distribuidora, na quantidade correspondente à energia elétrica ativa injetada na rede de distribuição pela mesma unidade consumidora, ou seja, a cobrança de PIS/Pasep e COFINS começou a ser realizada com base no consumo líquido da unidade consumidora, como transcrito a seguir:

\begin{abstract}
Art. 8 Ficam reduzidas a zero as alíquotas da Contribuição para o PIS/Pasep e da Contribuição para Financiamento da Seguridade Social - COFINS incidentes sobre a energia elétrica ativa fornecida pela distribuidora à unidade consumidora, na quantidade correspondente à soma da energia elétrica ativa injetada na rede de distribuição pela mesma unidade consumidora com os créditos de energia ativa originados na própria unidade consumidora no mesmo mês, em meses anteriores ou em outra unidade consumidora do mesmo titular, nos termos do Sistema de Compensação de Energia Elétrica para microgeração e minigeração distribuída, conforme regulamentação da Agência Nacional de Energia Elétrica - ANEEL. (BRASIL, 2015).
\end{abstract}

A tributação ambiental vem auxiliando o país desenvolveu várias políticas públicas através de programas que visam a fomentação e o desenvolvimento da indústria fotovoltaica, esses projetos são voltados a concessão de benefícios fiscais 
no âmbito da energia solar fotovoltaica, sempre visando a diversificação da matriz energética nacional, a segurança de energia, a promoção de competitividade e a inovação do setor.

\section{CONSIDERAÇÕES FINAIS}

A inserção das energias renováveis se faz de extrema importância para o desenvolvimento socioeconômico e ambiental, visando diversificar a matriz energética e trazendo a possibilidade de evitar problemas de faltas de energia como os chamados apagões que já ocorreram no país, além de evitar que o país fique cativo de fontes não renováveis, os combustíveis fósseis que, além de ser uma fonte cara, possuem grande impacto ambiental.

O Brasil possui um alto nível de irradiação solar e, também, a maior reserva de silício do mundo. Entretanto a falta de desenvolvimento tecnológico fez com que a matéria prima abundante fosse exportada em seu estado bruto, a preços modestos, para que então consumidores cativos das concessionárias de energia elétricas que quisessem gerar sua própria energia viessem a importar essa matéria prima industrializada de outros países como Alemanha, Japão e China.

Desde 2012, o país vem investindo no setor de energia solar e muito das políticas públicas vem fomentando o setor, a exemplo das isenções de ICMS, PIS e COFINS, que foram um importante passo no desenvolvimento do setor fotovoltaico, abrindo maior viabilidade econômica, essa extrafiscalidade se dá pela essencialidade do setor.

Portanto, com um planejamento governamental, elaborado através de políticas públicas de tributação extrafiscal, financiamentos, investimentos e pesquisas, o desenvolvimento tecnológico impulsionará as indústrias nacionais promovendo assim um desenvolvimento do setor fotovoltaico, o que garantirá uma maior sustentabilidade, em vista da utilização de energia limpa e renovável. 


\section{REFERÊNCIAS}

AZEVEDO, F. M.; BRAGA JUNIOR, S. A. M. A produção de biocombustíveis no Brasil na promoção do desenvolvimento sustentável: uma análise das implicações socioambientais. In: Xavier, Y. M. A. et al. Direito das energias renováveis e desenvolvimento. Natal, RN: EDU-FRN, 2013. p. 75-105.

BETTES, J. M. et al. O direito entre o desenvolvimento e a sustentabilidade. Curitiba: CRV, 2017. 352 p.

BRASIL. Constituição da República Federativa do Brasil, promulgada em 5 de outubro de 1988. Brasília, 1988.

BRASIL. Lei no 12.187, de 29 de dezembro de 2009. Brasília, 2009.

BRASIL. Lei no 13.169, de 6 de outubro de 2015. Brasília, 2015.

BREMBATTI, K. Governo propõe isenção de ICMS para pequenos geradores de energia. Gazeta do Povo, Curitiba, 6 jun. 2018. Disponível em: $<$ https://www.gazetadopovo.com.br/politica/parana/governo-propoe-isencao-de-icmspara-pequenos-geradores-de-energia-1 kmj2awp5bqorlog69h2yhzh5/>. Acessado em: 15 set. 2019.

CAVALCANTI, C. C. T. O direito da energia no contexto ibero-brasileiro. Rio de Janeiro: Synergia, 2017. 400 p.

CORBETTA, J. M. Taxa ambiental como instrumento de política pública na defesa do meio ambiente. In: CAVALCANTE, D. L.; CALIENDO, P. (Coord.). Políticas públicas, tributação e energia solar, Curitiba: CRV, 2017. p. 43-66.

LO VISCO, M. Legislação Tributária para Concursos da Receita Federal, 3. ed. Niterói: Impetus, 2017. 729 p.

MENDES, G. F. et al. Direito, Inovação e Tecnologia, v. 1, Brasília: Saraiva, 2016. $479 \mathrm{p}$.

MONTERO, C. E. P. Tributação ambiental: Reflexões sobre a introdução da variável ambiental no sistema tributário. São Paulo: Saraiva, 2014. 392 p.

MONZONI, M. (Coord.). Financiamento para energia solar fotovoltaica em geração distribuída. São Paulo: FGVces, 2018. 75 p. 
OLIVEIRA, C. N. N. Isenção de IPI para painéis de energia solar fotovoltaica. In: CAVALCANTE, D. L.; CALIENDO, P. (Coord.). Políticas públicas, tributação e energia solar. Curitiba: CRV, 2017. p. 115-32.

SEBASTIÃO, S. M. Tributo ambiental: Extrafiscalidade e função promocional do direito. Curitiba: Juruá, 2006. 352 p.

SILVA, J. A. da. Direito Ambiental Constitucional. 10. ed. São Paulo: Malheiros, 2013. $374 \mathrm{p}$.

VALADÃO, M. A. P.; CARNAÚBA, F. R. A extrafiscalidade como forma de implementação do desenvolvimento sustentável. In: CAVALCANTE, D. L.; CALIENDO, P. (Coord.). Políticas públicas, tributação e energia solar. Curitiba: CRV, 2017. p. 83-114.

WEDY, G. Tributação, energias renováveis e desenvolvimento sustentável. In: CAVALCANTE, D. L.; CALIENDO, P. (Coord.). Políticas públicas, tributação e energia solar. Curitiba: CRV, 2017. p. 21-42. 